\title{
Computing: Early Days
}

\section{Robin Wilson and Martin Campbell-Kelly}

mathematical tables and print the results. Never built during his lifetime, a full-scale working version was constructed from his detailed drawings in 1991. It resides in the Science Museum in London.

Babbage's analytical engine can be regarded as the forerunner of the modern programmable computer. Designed to be run by steam power, it contained a store (or memory) and was to be programmed by means of punched cards with holes in specific locations to convey information. Babbage got the idea of using punched cards from the "Jacquard loom," invented by Joseph Marie Jacquard (17521834) to mechanize the weaving of complicated patterns.

Data processing with punched cards was developed by Herman Hollerith (1860-1929) for the United States population census of 1890. Punched paper tape based on the binary system was used in telegraph systems. Both punch cards and paper tape were in widespread use for many years for computer input and output. conceived in the 1820s, was a complex arrangement of gears and levers designed to mechanize the calculation of

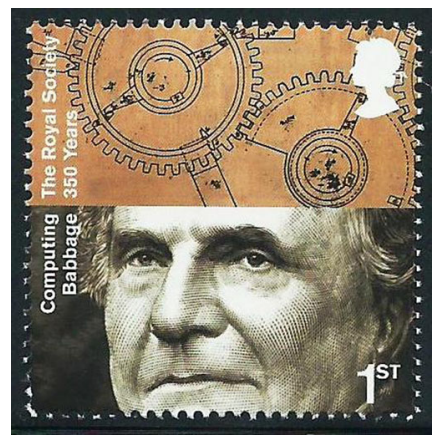

Charles Babbage

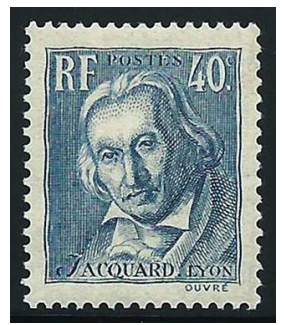

Joseph Marie Jacquard

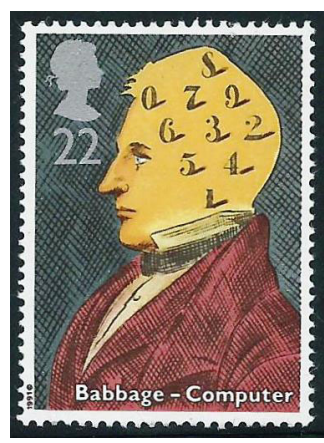

Charles Babbage

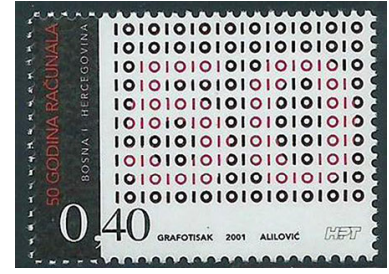

Binary system

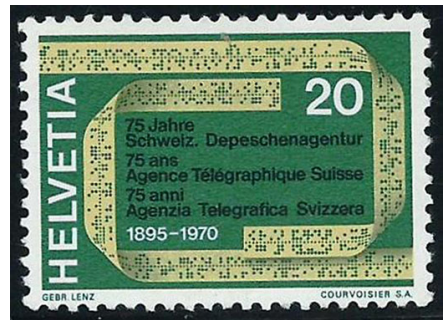

Punched paper tape

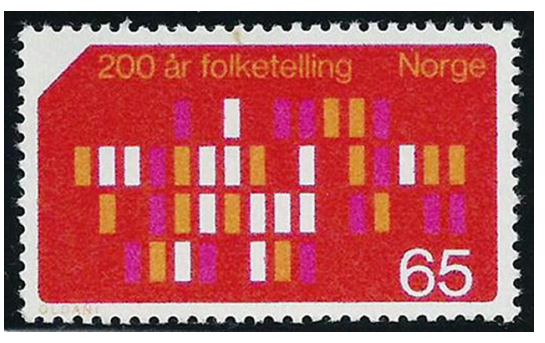

Punched card
Publisher's Note Springer Nature remains neutral with regard to jurisdictional claims in published maps and institutional affiliations

\footnotetext{
> Column editor's address: Robin Wilson, Mathematical Institute, Andrew Wiles Building, University of Oxford, UK

e-mail: r.j.wilson@open.ac.uk

Martin Campbell-Kelly

Department of Computer Science

University of Warwick

Coventry CV4 7AL, U.K.

e-mail: m.campbellkelly@gmail.com
} 